\title{
La tradición moderna y la edición del Romancero hispánico. Encuestas promovidas por Ramón Menéndez Pidal en Asturias (1911-1920)
}

1. LOS ROMANCES DE LA TRADICIÓN ORAL MODERNA EN LOS PROYECTOS DE EDICIÓN GLOBAL DEL ROMANCERO EN EL SIGLO XX

El hallazgo de la pervivencia tradicional del Romancero en el área castellana, en 1900, llevó a Menéndez Pidal y a María Goyri a conceder una atención preferente a la exploración de campo. Hasta 1910 recogerán personalmente gran número de versiones de la tradición oral moderna en distintas provincias (sobre todo en Asturias, León, Segovia y Madrid), al mismo tiempo que estudiaban las fuentes impresas y manuscritas del romancero viejo, y los testimonios de la vitalidad del género en los siglos XVI y XVII o posteriores. El estudio de la vigencia del Romancero, según se reflejaba en las obras de autores cultos, fue labor en gran parte de María Goyri que despojó la producción de los escritores clásicos, con una exhaustividad y amplitud que hoy nos admira, en busca de citas literales y otros ecos de romances. Menéndez Pidal simultaneó estas tareas instrumentales con la redacción de buen número de trabajos dedicados a aspectos teóricos varios sobre la transmisión oral, la relación del Romancero con la épica medieval y la balada europea, y al estudio de romances específicos de acuerdo con métodos e intereses muy variados. Esas distintas facetas en el estudio del Romancero hispánico no siguieron, sin embargo, líneas paralelas dentro de la actividad científica de Menéndez Pidal. Nos interesa aquí, en concreto, dilucidar las razones de su «discontinuidad» en la exploración de la tradición moderna.

A partir de 1911 la intervención directa de Ramón Menéndez Pidal en la recolección de campo es esporádica. En contraste con su actividad en la década anterior, Menéndez Pidal sólo anotó personalmente colecciones unitarias de romances de modo no sistemático: en la sierra de Gredos en 1926 (en viaje vacacional realizado junto con su hijo Gonzalo y Claudio Sánchez Albornoz) ${ }^{1}$, y, ya en 1930, en los valles orientales

1 La excursión de agosto de 1926 fue evocada, y aderezada con comentarios poco pertinentes "para el interesado en la tradición oral, en un artículo de C. SÁNCHEZ ALBORNOZ, recogido en De ayer $y$ de hoy. Temas históricos, semblanzas, nostalgias (Madrid: Taurus, 1958), pp. 99-107. 
de León en una encuesta que tenía por objeto ampliar sus estudios sobre las fronteras del dialecto leonés. Resulta especialmente llamativo, por ejemplo, el que entre las otras muy escasas versiones aisladas recogidas por don Ramón después de 1910 no se cuenta ningún texto de romances asturianos, con sólo una excepción poco significativa ${ }^{2}$, pese a que tuvo varias ocasiones para ampliar el conocimiento del Romancero de una zona a la que se hallaba vinculado por razones de toda índole, desde las familiares a los estudios dialectológicos, y cuya riqueza en cuanto a poesía tradicional no se le ocultaba en modo alguno.

Creemos que el año de 1910 marca, en efecto, una línea divisoria en los trabajos de Menéndez Pidal sobre el Romancero. En octubre de 1909, con vistas a unas conferencias pronunciadas en la Universidad de Columbia, realiza con la ayuda de María Goyri un recuento global de las versiones de romances que hasta entonces había reunido en su archivo; y del año siguiente son unos inventarios muy detallados, por provincias y por colecciones individuales, de todos los textos de que disponía hasta entonces. Sin embargo, en los años sucesivos, pese al continuado interés del matrimonio Menéndez Pidal-Goyri por el Romancero y al ininterrumpido enriquecimiento de su archivo, esos inventarios no serían nunca actualizados ${ }^{3}$. Es muy probable que - ya en 1910 - el conocimiento de la riqueza extraordinaria de la tradición oral moderna del Romancero hispánico, hubiera llevado a Menéndez Pidal al convencimiento de que esas versiones no podían ser ya un simple apéndice a los textos del siglo XVI.

Esa parecía haber sido, sin embargo, la concepción primera de Menéndez Pidal al esbozar un primer proyecto de edición del Romancéro. Este plan primitivo de publicación plenaria de los romances españoles surgió en 1901 a raíz de un proyecto de colaboración propuesto por Foulché-Delbosc. Menéndez Pidal no se mostró al principio muy favorable a este proyecto, porque estimaba que podía no contar con la aprobación de su maestro Menéndez Pelayo, quien por entonces publicaba los volúmenes correspondientes al Romancero en su Antología de poetas

\footnotetext{
2 Menéndez Pidal anotó los incipit de dos romances vulgares en Arenas de Cabrales (agosto de 1930) con motivo de un viaje a Llanes y Arenas de Cabrales realizado para observar las antiguas danzas romancísticas, el «Pericote», y el "Corricorri», en funciones que se organizaron en su honor. Acerca de este viaje, cf. las noticias de F. Carrera, «Don Ramón Menéndez Pidal en Llanes», El Oriente de Asturias, 9 (agosto de 1930), y otra crónica, anónima, con el mismo título publicada en El Pueblo de Llanes, el mismo día.

Cf. D. Catalán, «El romancero de tradición oral en el último cuarto del siglo XX», en El Romancero boy: Nuevas fronteras (Madrid: Gredos, 1979), p. 223.
} 
líricos castellanos, y porque las relaciones entre Foulché-Delbosc y Menéndez Pelayo no eran, en aquel momento, las mejores. Finalmente accedió a compartir con el estudioso francés una labor en la que, según reconoció Foulché, el joven Menéndez Pidal le llevaba la delantera. La propuesta de trabajo conjunto en una edición del Romancero la formula Foulché-Delbosc por primera vez en una carta del 25-VI-1901:

En vista de su última carta, se me ocurre hacerle a V. una proposición, pero ha de ser con condición de que si no le agrada V. me lo dirá sin que sea preciso entrar en explicaciones. ¿Tendría V. inconveniente en publicar conmigo una edición de romances viejos? Si V. me dice que admite mi proposición, me comprometo en utilizar cuanto pueden tener las bibliotecas de París, Londres, y - si posibleViena; V. tendría que arreglarse con las de Madrid y la del marqués de Jerez en Sevilla, así como con las demás de España en que se pueda encontrar algo relativo a los romances. Si V. prefiere publicar solo el Romancero, no publicaré yo ninguno, limitándome a un muy corto artículo de revista y mandándole a V. cuanto tengo copiado hasta hoy día. Si colaboramos, nuestro Romancero podría salir en la «Bibliotheca hispánica» sin gastos para V., y partiríamos igualmente la ganancia, si la hay. Creo que en un par de años, sin tener prisa, podríamos acabar la tarea, empezando la impresión en octubre de 1903.

V. dirá lo que opina de la idea, pero conste que no quisiera molestarle, ni contrariarle en algo; por eso le ruego me diga su parecer, y esté $\mathrm{V}$. cierto que cualquiera que sea su decisión estaré conforme. V. pensó en los romances mucho antes que yo y ha de quedar enteramente dueño de su determinación ${ }^{4}$.

En unas notas tomadas al dorso de esta carta, Menéndez Pidal refleja haber querido renunciar al proyecto; la negativa era, al principio, categórica, y una de las razones para esa negativa era precisamente el papel que las versiones de la tradición moderna tenían dentro de su propio plan de edición del Romancero:

Siento perder colaboración preciosa del que ha probado ser el que mejor entiende lo que es la publicación de textos. Pero me parece muy difícil repartir el trabajo en cuanto a los textos, e imposible en cuanto a las notas. Además, la colaboración destruiría mi plan, que es comprender también los [romances] tradicionales de hoy, de que ya tengo buena colección de inéditos.

Posteriormente, sin embargo, Menéndez Pidal decidió contestar dejando abierta la posibilidad de colaborar con su, por entonces, amigo francés; aunque señalaba también algunas dificultades que veía en el

4 Esta carta, como las demás que citaremos de la correspondencia entre FoulchéDelbosc y Menéndez Pidal, se conserva actualmente en el Archivo Menéndez Pidal. 
proyecto. En sus notas últimas a la carta de Foulché-Delbosc, Menéndez Pidal apunta:

Contesto que hablaremos. Que con [la] colaboración se gana en riqueza y rapidez, pero se pierde en personalidad; precisamente la apreciación del estilo de los romances es delicada (no coincido en llamar 'viejo' a secas al de F. D. de los Infantes) ${ }^{5}$. Pese V. el pro y el contra, y hablaremos.

En la carta definitiva (de julio de 1901, posiblemente), que desconocemos, a la que responden estos borradores, Menéndez Pidal hubo de manifestarse más inclinado aún a colaborar con Foulché-Delbosc, y añadió algunas observaciones sobre la copia de ediciones antiguas de romances con las que el hispanista francés, que dio ya por hecho que el proyecto se llevaría a cabo, se mostró conforme ${ }^{6}$. En una carta posterior, del 31 de octubre, Pidal volvió a manifestar, y con mayor claridad, las dificultades que veía en el Romancero preparado conjuntamente; y es de nuevo el tratamiento o exclusión de la tradición moderna lo que motiva sus mayores reticencias. Aparece también aquí una alusión directa a los romances recogidos por él en Asturias y otras regiones:

Siento mucho que no haya podido venir a Madrid para acordar si colaboramos o no en el Romancero, y trataré de decirle en pocas líneas lo que se me ocurre.

El Romancero en que yo había pensado (tachado y sustituido por: que yo preparo) hace tiempo, tiene dos partes: una de romances tradicionales recogidos en el siglo XVI; otra de los tradicionales recogidos en nuestros días (tachado: modernamente en el XIX), para ofrecer así dos sondajes de la tradición con tres siglos de intervalo. Tengo ya recogidos directamente por mí bastantes romances inéditos de Asturias, Soria ${ }^{7}$, y algunas procedentes de otras provincias

5 Menéndez Pidal alude al romance «En un monte junto a Burgos», copiado en un manuscrito del siglo XVI, descubierto y publicado por FoulchÉ-DelBoSC, "Un romance retrouvé», Revue bispanique, V (1900), pp. 251-254.

6 Foulché-Delbosc escribía el 7 de octubre de 1901: «No me fue posible pasar por Madrid: no necesito decirle a $\mathrm{V}$. cuánto lo siento, ya que me proponía pasar con $\mathrm{V}$. algunos días agradabilísimos hablando de nuestro proyectado Romancero. Tuve tanto que hacer en Barcelona que hube de renunciar al viaje a la villa y corte [...] Su última carta ya tiene tres meses de fecha y apenas me explico cómo no me ha sido posible escribirle a V. antes; su amistad me dispensará, y V. me comunicará cuanto pensaba decirme sobre el asunto del Romancero. Claro que estoy conforme con cuanto V. decía de las ediciones que copiar o cotejar, y podemos empezar cuando V. lo desee. Dígame V. cómo le parece que hemos de hacer para no perder tiempo y ahorrar trabajos dobles e inútiles.»

7 Los romances de Soria son los recogidos en la primavera de 1900 en el curso de las investigaciones cidianas del matrimonio Menéndez Pidal. Don Ramón enumeró los textos recogidos en carta a Menéndez Pelayo, que éste transcribe parcialmente en el vol. X de la Antología de poetas líricos (Madrid, 1900), pp. 220-222. 
(tachado: Andalucía); y creo que algunas otras (tachado: dos o tres) exploraciones que proyecto podrán ofrecer un conjunto nuevo en la materia. Si nos asociamos, tendré que omitir esta segunda parte, pues es imposible la colaboración en ella. Además, nos habremos de limitar al simple texto de los romances, sin notas literarias; pues de no residir $V$. aquí sería muy difícil repartirnos el trabajo. Sólo esta tarea de renovar el texto de Wolf sería utilísima, como V. dice muy bien $[\ldots]$

Si V. se decide por que hagamos juntos el Romancero, renunciaré gustoso a mi plan (que abarcaba también los romances tradicionales de hoy) para ofrecer junto dos sondajes de la tradición con tres siglos de intervalo.

Que publique él sus romances, que me envíe sus materiales, o que colaboremos, decida él y yo me conformo con todo ${ }^{8}$.

El proyecto de edición conjunta del Romancero parecía, pues, estar bien encaminado, aunque Foulché-Delbosc no quiso cumplir del todo las condiciones de índole personal que su colega español estimaba irre-

8 Borrador de carta, 31-X-1901. La parte central de esta carta estaba dedicada a otro tipo muy distinto de dificultades que Menéndez Pidal veía en la colaboración con Foulché-Delbosc, es decir las que se derivaban del posible desagrado que su maestro, Menéndez Pelayo, podía sentir ante tal colaboración. Un primer reparo, el de ocuparse del Romancero cuando don Marcelino trabajaba sobre ese campo, no le parecía a Pidal obstáculo insalvable: «Estando todavía en publicación el Romancero de Menéndez Pelayo acaso no le pareciera bien que yo preparara otro; pero a esto no doy importancia, pues creo tampoco se la daría él. Cualquiera es dueño de renovar los asuntos que otro ha tratado, aun antes de los dos o tres años que tardaría el nuevo Romancero». Mayores problemas veía en la enemistad que había surgido entre su maestro y el amigo francés con motivo de una reseña crítica que Foulché-Delbosc había publicado, en 1900, de la edición de la Celestina preparada por Menéndez Pelayo. Pidal creía posible recomponer la buena relación entre ambos eruditos, y para ello sugería a Foulché que redactara y publicara en la Revue bispanique una reseña alabando lo mucho que había que alabar en los últimos volúmenes de la Antología de poetas líricos castellanos: «Si se dijese del Romancero de la Antología que el texto no valía nada, pero que ofrece grandes y notables novedades como son la tercera parte de la Silva, varios pliegos sueltos y la reunión en un cuerpo de los romances recogidos hoy de la tradición oral, no se diría ninguna mentira». Menéndez Pidal insiste en que era para él condición básica que Foulché solucionase sus diferencias con Menéndez Pelayo, y que no estaba dispuesto a arriesgar su relación personal con su maestro, lo que creía seguro en las circunstancias de entonces: «Pero que yo colaborase con $\mathrm{V}$. de seguro enemistaba conmigo a mi maestro, a quien tanto debo; y este reparo no le chocará a V. ni lo tomará por escrúpulo monjil»; y, más adelante: «Espero no sospeche V. que en esto hago de apóstol o de corredor de Menéndez Pelayo; creo que $\mathrm{V}$. me conoce y yo le conozco de sobra para saber que su integridad científica no le permitiría alabar lo que no sea loable. Sólo quisiera ponerme en libertad de poder disfrutar de la colaboración de V. para bien del proyectado Romancero.» 
nunciables 9. En la última carta que conocemos que alude a este proyecto, del 6 de noviembre de 1901, el estudioso francés creía que Menéndez Pidal no debía dar tanta importancia a sus desavenencias con don Marcelino; respecto al Romancero en sí, Foulché-Delbosc veía factible emprender ya el trabajo y no se oponía, incluso, a dar entrada también a los romances de la tradición moderna:

En cuanto a nuestro Romancero, como no lo haríamos para el mismo público que el de la Antología, creo que Menéndez y Pelayo no tendría motivo de enfadarse; y, además, resultaría una obra casi completamente distinta de la suya.

Me encargaré de lo de París y Londres, como V. me lo indica, así como de buena parte de las bibliotecas de España. ¿Piensa V. dar una vuelta por Austria y Baviera el año que viene?

Los romances tradicionales y el estudio literario serían cosas de V., y de V. solo, y podrían colocarse más tarde en un nuevo tomo que vendría a ser un suplemento o una segunda parte de nuestra obra común. No me haga V. esperar su contestación y dígame lo que opina de cuanto acabo de decirle, con la persuasión de que comprendo perfectamente sus reparos y cavilaciones, y de que nada de cuanto se le ocurre en el presente asunto puede chocarme.

Creemos que los «reparos y cavilaciones» que experimentaba Menéndez Pidal eran de mayor entidad que lo que podía suponer FoulchéDelbosc. Motivos personales aparte ${ }^{10}$, el plan al que se reducía el proyecto del estudioso de París no podía resultar satisfactorio para Menéndez Pidal. Una simple renovación de la Primavera de Wolf, por útil que fuese, no era un objetivo muy atrayente, y menos estando tan próxima la reedición de Menéndez Pelayo. A Foulché-Delbosc le interesaba únicamente el Romancero viejo, y ello sólo en su aspecto estrictamente textual; lo que llama «estudio literario» le era indiferente, y más aún todo cuanto tuviera que ver con la tradición oral moderna; ya hemos visto que consideraba esos aspectos sólo como un «suplemento» que podía confiarse a la labor en solitario de Menéndez Pidal,

9 En su contestación a la carta de Pidal antes citada, Foulché-Delbosc se manifestaba dispuesto a hacer la reseña elogiosa de los últimos tomos de la Antología, pero a la vez anunciaba que tendría que oponer algunos reparos y quejas, por presuntos agravios recibidos del maestro español, que - según él mismo reconoce- «enfurecerían» aún más a Menéndez Pelayo. En sus anotaciones directas para responder a esta carta, Menéndez Pidal escribe: «Contesto 10 Noviembre, que haga la reseña franca y no chapuzada y que hablaremos de unificar nuestros trabajos.»

10 Foulché-Delbosc, por ejemplo, no escribió nunca la reseña elogiosa y «franca» sobre la Antología de Menéndez Pelayo, en la que Pidal tanto había insistido. Fue el propio Menéndez Pidal quien acabaría publicando esa reseña: «El Romancero de Menéndez Pelayo», La Lectura, III (1903), pp. 55-64. 
mientras que la «obra común» había de basarse en la copia de pliegos sueltos y colecciones antiguas de distintas bibliotecas europeas. De ahí su sorprendente optimismo al calcular en «un par de años, sin tener prisa» el tiempo necesario para dar cima a la tarea; un optimismo que compartía también Menéndez Pidal, si de lo que se trataba era sólo de editar los textos impresos en el siglo XVI ${ }^{11}$.

Así pues, Menéndez Pidal estuvo dispuesto, como se deduce de su correspondencia con Foulché-Delbosc, a colaborar en la publicación de un Romancero concebido en los términos del estudioso francés. Pero por esa misma correspondencia sabemos también que Pidal tenía en mente ya por entonces un tipo de edición muy distinta, y que aceptó sólo tras muchas reticencias y sin dar nunca su aprobación definitiva al proyecto. De hecho, ninguna nueva referencia al plan conjunto volvemos a hallar después de 1901; en 1903, en carta a Morel-Fatio, habla ya de sus proyectos de un nuevo romancero en los que ningún papel jugaba la colaboración con Foulché-Delbosc:

Agradezco a Vd. el propósito de hablar con Halévy sobre sus romances judíos. Ojalá este señor no los tenga olvidados y los deje sin publicar. El romancero de Menéndez Pelayo me renovó la idea de recoger romances publicados e inéditos y espero reunir versiones en gran cantidad, para cuando la obra de Menéndez Pelayo haya hecho su camino, planear un nuevo romancero ${ }^{12}$.

Y cuando Carolina Michaëlis en sus artículos de 1907 a 1909 alude al gran proyecto de un «Romanceiro Hispanico» o de un «Romanceiro geral hispano-português» lo consideraba ya una labor exclusiva de Menéndez Pidal y María Goyri en la que habrían de integrarse también los materiales portugueses de José Leite de Vasconcellos ${ }^{13}$. Al rememorar, mucho tiempo después, los años en que empezó a planear su obra magna sobre el Romancero, Menéndez Pidal sólo menciona su proyecto propio y nos indica - en 1943 - cómo lo había concebido ya entonces:

11 Recuérdense «los dos o tres años que tardaría el nuevo Romancero» en la carta de Menéndez Pidal cit. supra.

12 Carta a A. Morel-Fatio, 18-V-1903, publicada por J. Lemartinel, «Cartas de Menéndez Pidal a Morel-Fatio», Cuadernos hispanoamericanos, 238-240 (1969), p. 255.

13 Cf. C. MiChaËLIS DE VASCONCEllos, «Estudos sobre o Romanceiro peninsular. Romances velhos em Portugal», Cultura Española, V (1907) a XIV (1909). Hay tirada aparte en forma de libro (Madrid: Impr. Ibérica, s. a. [1910]), y reediciones en Coimbra: Imprensa da Universidade, 1934; y Porto: Lello \& Irmão, 1980. Véase en especial la dedicatoria, «aos futuros e definitivos apuradores do Romanceiro geral hispanoportuguês...», y otras alusiones en las pp. 284, 286 y 332 (cito por la ed. de 1910). 
Cuando yo era todavía un estudiante y tuve la fortuna de tratar en Madrid con [...] don José Leite de Vasconcellos, el Romancero era ya asunto de nuestras conversaciones y él me comunicó más tarde algunos romances inéditos, por él recogidos. Luego, formé el propósito de publicar el Romancero en toda su extensión portuguesa, castellana y catalana, en colaboración con mi mujer, muy conocedora de la tradición popular [subrayamos], y ambos promovimos y a ambos nos está dedicado el magistral trabajo de nuestra inolvidable amiga doña Carolina Michaëlis de Vasconcellos sobre Romances velhos em Portugal ${ }^{14}$.

En el mismo sentido se expresa Menéndez Pidal en 1953, en las palabras preliminares de la obra que consideraba como estudio previo a la edición del Romancero Tradicional de las Lenguas Hispánicas. Se proporcionan aquí algunas precisiones cronológicas que nos interesa especialmente recoger:

La publicación de una nueva y amplísima colección de romances es proyecto acariciado por mí desde la juventud, y siempre dilatado, por lo mismo que era tan grato y tan deseoso de mejora [...]. Ya va para medio siglo que, refiriéndose a ese proyecto, la insigne romanista germano-portuguesa, Carolina Michaëlis [...] anunciaba la definitiva reconstrucción del Romancero hispano-portugués; y sin embargo, la ardua empresa no ha sido aún realizada, habiéndose publicado tan sólo estudios y más estudios como labor preparatoria.

Los augurios esperanzadores de la señora Michaëlis se fundaban en empeñosos trabajos que, dedicados a descubrimientos e indagaciones romancísticas, hacíamos por entonces, tanto el gran etnólogo Leite de Vasconcellos en Portugal, como mi mujer y yo en España [...] Por lo que toca a nosotros, era empresa impulsada el año inicial de este siglo con grandes afanes, continuada después siempre como afición doméstica, como simbólico emblema familiar [...] Y esa afición, propagada a amigos y discípulos, daba por resultado en el primer decenio, además de una variada serie de estudios romancísticos, una muy abundante colección de romances hallados en las bibliotecas de España o del extranjero, y rebuscados en la tradición oral ${ }^{15}$.

Parece, pues, evidente que una edición del Romancero que prescindiese de las versiones aportadas por la tradición moderna fue desechada muy pronto por Menéndez Pidal; y, en consecuencia, el proyecto de trabajar conjuntamente con Foulché-Delbosc debió de ser abandonado

14 R. MEnÉndez PIDAL, «Poesía tradicional en el Romancero Hispano-Portugués», Boletim da Académia das Ciências de Lisboa, XV (1943), pp. 5-31. Reed. en Castilla: la tradición, el idioma (Madrid: Espasa-Calpe, 1945), pp. 41-73; y en Estudios sobre el Romancero (Madrid: Espasa-Calpe, 1973), pp. 379-401. Cito por esta última ed., p. 381.

15 R. MENÉndez PIDAL, Romancero hispánico, pp. ix-x. 
antes de que se llegara a iniciar trabajo alguno. $\mathrm{Y}$ ello mucho antes de que se produjera la ruptura entre ambos estudiosos ${ }^{16}$.

De las citas que hemos aducido se desprende la gran importancia que ya desde 1901 Menéndez Pidal atribuía a la tradición moderna, equiparable a la de los textos del Romancero viejo. Esta convicción fue haciéndose más firme en los años inmediatamente posteriores, y resultaba una novedad en el ámbito del Romancero español. Su concepción del Romancero como un conjunto indivisible en el que debían editarse simultáneamente todos los testimonios textuales es tanto más destacable si se tiene en cuenta que - según creemos- por esas fechas Menéndez Pidal desconocía aún los grandes modelos de edición de los corpora de la baladística europea, es decir los establecidos por Francis J. Child y por Svend Grundtvig para la poesía narrativa anglo-escocesa y danesa respectivamente. Esas magnas obras, ya terminada entonces la de Child (1882-1898) y muy avanzada la de Grundtvig (seis volúmenes editados entre 1853 y 1898), incluían junto a estudios pormenorizados de cada

16 La ruptura sonada y especialmente violenta, tuvo lugar sólo en 1912, aunque puedan rastrearse antecedentes; el apoyo de R. Menéndez Pidal al Bulletin hispanique, auspiciado por Cirot y Morel-Fatio fue visto por Foulché como poco menos que una traición a su propia revista - la Revue hispanique- y a él mismo. La amistad se interrumpió formalmente, sin embargo, sólo como consecuencia de la publicación por FoulchéDelbosc de su Essai sur les origines du Romancero. Prélude (Paris: F. Paillart, 1912); el Essai apareció poco después en traducción española de Lucas de Torre, «con autorización [o, más bien, 'por instigación'] del autor», en Madrid, 1914. El folleto era, en realidad, una crítica, en tono ciertamente poco amable, a algunas apreciaciones del libro de Menéndez Pidal, L'Epopée castillane à travers la littérature espagnole (Paris: A. Colin, 1910). Al Essai respondió Menéndez Pidal, y también en tono subido, en una reseña extensa publicada en la Revista de Libros, II, núm. 8 (1914), pp. 3-14; reimpresa con el título de «Los orígenes del Romancero» en El Romancero. Teorías e investigaciones (Madrid: Páez, s. a. [1928]), pp. 61-85, y en Los romances de América y otros estudios (Buenos Aires: Espasa-Calpe, 1939), pp. 101-122. La hostilidad duró hasta el fin de la vida de Foulché-Delbosc (1864-1929), y la polémica alcanzó un inesperado desarrollo cuando Foulché acogió en su Revue hispanique un extenso trabajo de Julio Cejador, «El Cantar de Mio Cid y la Epopeya castellana», R. Hisp., XLIX (1920), pp. 1-310, que era en rigor una desfasada censura de las tesis sostenidas por Menéndez Pidal. En la Revista de Filología Española apareció una amplia recensión del estudio de Cejador con el título de «La epopeya y los romances españoles. Examen de una antigua teoría», RFE, VIII (1921), pp. 5-12. Aunque no aparece firmada, creemos indudable que la reseña fue redactada por Menéndez Pidal, en colaboración, acaso, con algún discípulo cercano, que muy bien pudo ser Américo Castro. La reseña utiliza un lenguaje insólito para la mesura de que en otras polémicas hizo gala Menéndez Pidal, quien no se recató en señalar que detrás de las «absurdas e indecorosas» afirmaciones de Cejador estaba la mano de un Foulché-Delbosc, «deseoso de vengar el fracaso de cierto Prélude al que no pudo seguir sinfonía alguna». 
balada (las «notas literarias» que preveía Pidal), todos los textos, con independencia de su fecha de recogida. Es cierto que las versiones modernas no representan en esas tradiciones un interés y un volumen comparable al que por entonces ya se podía predecir que tendrían en el Romancero hispánico. Sin embargo en la obra más ambiciosa sobre el Romancero publicada hasta entonces, es decir los cinco volúmenes dedicados por Menéndez Pelayo al género en su Antología de poetas líricos castellanos, el editor mantenía rigurosamente la separación cronológica y los romances de tradición moderna no se integraban orgánicamente con sus antecesores de los siglos XV y XVI; figuraban sólo como un apéndice, entre otros, y compartimentados según su procedencia regional (romances de Asturias; romances de Andalucía y Extremadura; romances de los judíos de Levante, etc.). Ese plan era también el de Foulché-Delbosc, suponiendo que al fin se diera entrada a las versiones recogidas recientemente. La nueva concepción de Pidal, fraguada en esos mismos años, resultaba, en cambio, más acorde con la que por entonces se había impuesto ya en otros países europeos.

La nueva perspectiva sobre el Romancero no fue ninguna «iluminación» repentina que se le impusiera a Pidal como una evidencia. En 1901 la vitalidad y la importancia de la tradición moderna era una realidad, todavía, sólo en Portugal y Cataluña, o en el Oriente sefardí. Los testimonios del área «central» o de lengua castellana eran aún muy escasos si se exceptúa, precisamente, la tradición asturiana. Los romances recogidos personalmente por Menéndez Pidal y María Goyri no eran aún muchos en número, aunque en la carta a Foulché-Delbosc se hablase de una «buena colección de inéditos», y entre sus versiones no abundaban las de interés excepcional si se hace abstracción de un hallazgo célebre, el romance de La muerte del principe don Juan ${ }^{17}$.

La realidad es que el período de mayor actividad de Menéndez Pidal en relación con la tradición moderna empieza justamente después del proyecto frustrado de edición del Romancero al que aquí nos hemos referido. Como hitos principales bastará con destacar, en primer término, la recogida personal de nuevas versiones asturianas en 1902, y, proba-

17 Las versiones recogidas en Asturias por Menéndez Pidal eran poco más de diez, y otras tantas las de Soria y Burgos, a juzgar por el inventario que hace en la carta a Menéndez Pelayo citada antes (supra, nota 7). La identificación del texto de Burgo de Osma como una versión de un romance histórico, La muerte del príncipe don Juan, no fue inmediata a su hallazgo en 1900. El estudio de María GOYRI, que utilizaba ya otras versiones, entre ellas una asturiana de Santa Eulalia de Allande, se publicó algunos años después: «Romance de la muerte del príncipe Don Juan (1497)», Bulletin Hispanique, VI (1904), pp. 29-37. 
blemente el mismo año, otras de Almanza (León) anotadas a una criada en Madrid; mucho más numerosas son las versiones de Segovia, Madrid y Ávila recogidas en 1904-1905, y las de León y Asturias de 19091910 anotadas aprovechando excursiones dialectológicas. Pero mayor trascendencia tuvo el establecimiento de toda una red de colaboradores que en esta primera década del siglo empiezan, estimulados por Menéndez Pidal y siguiendo sus criterios metodológicos, a explorar la tradición oral en distintas áreas del Romancero. Entre 1904 y 1908 entró en contacto con algunos miembros de las comunidades sefardíes de Oriente (M. Gañi, Dan S. Albachary, Moisés Abravanel), o estudiosos de esa área cultural (como el conocido «apóstol» del sefardismo en España, el doctor Ángel Pulido, o el lingüista Max Leopold Wagner), y gracias a ello pudo incrementar su colección con nuevos textos judeo-españoles de Rumanía, Bosnia, Austria, Grecia y Turquía ${ }^{18}$. Especialmente productiva se revelaría la colaboración de José Benoliel, comenzada en 1904, que permitió empezar a descubrir la insospechada riqueza de la tradición sefardí en Marruecos.

En la Península, datan también de estos años unos contactos, que resultarían sumamente enriquecedores para el Romancero, con varios folkloristas y estudiosos locales de distintas regiones: con Rafael García Plata (1902), Ramos Hernández (1905), G. J. Núñez (1907), y otros, en Extremadura; con Francisco Salado (c. 1905) y José González (1908) en Zamora y León, Lomba y Pedraja (1906) en Santander, y un largo etcétera. En la conquista de «adeptos», o «incitados» (en el sentido que da a la palabra Américo Castro), a la causa del Romancero de la tradición moderna, ninguna adquisición se revelaría más trascendental que la del capitán de navío y músico Manuel Manrique de Lara (1863-1929), compositor de zarzuelas o «dramas musicales», historiador y crítico de la música contemporánea española y uno de los más destacados wagnerianos españoles. El propio Menéndez Pidal recordaría cómo se produjo la «catequización» de Manrique de Lara: En las tertulias que se celebraban en el domicilio que ocupaba Menéndez Pelayo en la Academia de la Historia «se hablaba mucho de estos temas, porque el maestro estaba entonces trabajando en su Tratado de los Romances viejos» ${ }^{19}$; Manrique de Lara se manifestaba escéptico respecto a la existencia de

18 Cf. S. G. ARmistead, El Romancero judeo-español en el Arcbivo Menéndez Pidal (Catálogo-indice de romances y versiones) (Madrid: C.-S. Menéndez Pidal, 1978), I, pp. 44-48.

19 El Tratado ocuparía los volúmenes XI y XII de la Antología de poetas líricos, publicados en 1903 y 1906. 
romances viejos en la tradición moderna después de haber intentado preguntar por ellos en distintas zonas, y Menéndez Pidal pudo convencerle de lo contrario después de una excursión, en julio de 1905, a Las Navas del Marqués, en Ávila. Además de presenciar la supervivencia de una antigua danza romancística, el «baile de tres», Manrique aprendió el «gran secreto que me daba buenos resultados» y que consistía en preguntar no por romances en general, «sino por versos determinados de tal o cual romance, que provocaban el recuerdo del interlocutor»; gracias a ello los excursionistas comprobaron que «todos con quien hablábamos tenían en su memoria algunos romances que copiábamos Manrique y yo, faltándonos manos para transcribirlos» ${ }^{20}$. La dedicación de Manrique de Lara a los trabajos del Romancero fue constante a partir de entonces y se reveló, en efecto, como una «adquisición inestimable», y ello no sólo en lo que atañe a las melodías. Aunque la mayor celebridad de las encuestas de Manrique suele ir referida a sus trabajos entre los sefardíes de Oriente (1911) y de Marruecos (1915-1916), no son de importancia inferior sus campañas de recolección de textos y melodías en la Península. Ya en 1906 contribuyó con versiones de Murcia y Albacete; de 1908 es una colección leonesa, y en años posteriores aportaría una de las contribuciones individuales más valiosas que se conservan en el Archivo Menéndez Pidal, con cientos de versiones de Castilla la Vieja, Cantabria y Andalucía, sobre todo.

Al mismo tiempo, la actividad universitaria de Menéndez Pidal facilitó la captación de otros colaboradores que en ese mismo primer decenio del siglo se incorporaron a la tarea de recogida de versiones de la tradición oral; y, poco después, la creación del Centro de Estudios Históricos y la colaboración de folkloristas de toda la Península permitió asegurar la recogida del Romancero tradicional y constituir un archivo de versiones que es hoy la fuente básica para los estudios en este campo.

Se comprende fácilmente el que una vez que don Ramón tuvo conciencia, gracias a su labor de recogida personal entre 1900 y 1910, de la amplitud del campo que era necesario cubrir antes de considerar satisfactorio el acopio de materiales romancísticos de la tradición oral mo-

20 R. Ment́ndez Pidal, Cómo vivió y cómo vive el Romancero (Valencia: La Enciclopedia Hispánica, s. a. [1945]), pp. 71-75. Reed. en Estudios sobre el Romancero, cit., pp. 432-435. El relato sobre la excursión a Las Navas del Marqués se reproduce en el Romancero Tradicional de las Lenguas Hispánicas, vol. VII (Madrid: C.-S. Menéndez Pidal, 1975), ed. de D. Catalán y J. A. Cid, pp. 110-115, junto con la versión de Gerineldo allí recogida y las transcripciones musicales de Manrique de Lara; el mismo relato, con alguna adición, figura en R. MENÉndeZ PIDAL, Romancero Hispánico, II, ed. cit., pp. 295-298. 
derna, no concibiera ya la empresa como una tarea que podía llevar a cabo por sí solo, ni que pudiera realizarse en el plazo de sólo unos cuantos años. Era necesario estimular y orientar la labor de un conjunto numeroso de corresponsales que trabajase en las distintas áreas del mundo hispánico. Ya en 1906-1907 elabora María Goyri su manual de «Romances que deben buscarse en la tradición oral», reeditado con modificaciones en 1929, que era facilitado a todo estudioso o simple aficionado que manifestaba interés por la poesía narrativa tradicional. Aunque la recogida no se realizara con la continuidad y sistematismo que hubieran sido de desear, lo reunido hasta la muerte de Menéndez Pidal, en 1968, formaba ya un corpus de extraordinaria riqueza que, a pesar de su carácter inicial de archivo "privado», se compara ventajosamente con los archivos establecidos con apoyo estatal y grandes recursos en la mayoría de los países europeos durante los siglos XIX y XX.

En las décadas siguientes de 1970 y 1980, la actividad de Diego Catalán y del Seminario Menéndez Pidal permitió incorporar varios miles de textos como resultado de varias campañas de encuesta realizadas entre 1977 y 1985, y del estímulo prestado a investigadores individuales que en algún momento colaboraron con el Seminario. El «Archivo Menéndez Pidal», completado con el «Archivo Sonoro del Romancero», que reúne las grabaciones de romances recogidos en las últimas etapas ${ }^{21}$, es hoy una rara muestra de lo que en nuestro país ha sido posible realizar cuando se combinan una iniciativa y una afición individual con la capacidad para estimular la colaboración desinteresada de personas de muy diferente condición. Lo que fue incapaz de llevar a cabo la desidia de unas instituciones públicas de un país que, independientemente de los avatares políticos, coincidían en rendir culto retórico a lo «popular», lo hicieron Ramón Menéndez Pidal en su ámbito familiar y en el Centro de Estudios Históricos, primero; y después, con un círculo expandido de discípulos y colaboradores próximos o distantes, Diego Catalán. Las tareas aún pendientes en el campo del Romancero, sin embargo, son de tal magnitud e implican la puesta a contribución de unos recursos, humanos y materiales, de tal envergadura que la simple edición de los textos, el Romancero Tradicional de las Lenguas Hispánicas, nos sigue pareciendo hoy una «tierra prometida» tan lejana como se le representaba en su ancianidad a Menéndez Pidal. Más lejana aún, si cabe, si se tiene en cuenta que la fragmentación y el hábito creciente de trabajar

21 Sobre el Archivo Menéndez Pidal y el A.S.O.R., cf. D. CATALÁN et al., Romancero e historiografía medieval. Dos campos de investigación del Seminario "Menéndez Pidal" (Madrid: Fundación Ramón Areces-Fundación Menéndez Pidal, 1989). 
en compartimentos estancos que afecta a todas las humanidades, resulta especialmente fatal para cualquier proyecto de tan largo alcance como lo es la edición plenaria del Romancero hispánico. Súmense a ello las incomprensiones institucionales y académicas que de hecho han paralizado la actividad del único equipo de trabajo, el «Seminario Menéndez Pidal», que gracias a sus colaboradores de dentro y fuera de la península estaba capacitado para llevar a término la tarea.

En espera de mejores tiempos, tal vez nos sirva de algún consuelo rememorar una de las etapas en las que el acopio de versiones de romances era todavía una labor esperanzada, inserta en un proyecto de futuro compartido por personas de muy distinta formación y distintos intereses profesionales o estéticos. La edición del «Romancero general español» se veía entonces como algo lejano, pero realizable; casi tanto como hoy nos parece irrealizable aunque próximo y posible. Entendámonos: por "próximo y posible» quiere aquí decirse que la tradición oral moderna está ya suficientemente explorada en una mayoría de las áreas del Romancero (con exceso, incluso, en varias de ellas, donde los materiales recogidos son hace tiempo «redundantes» en un elevadísimo porcentaje), o que, al menos, no existen ya lagunas significativas que justifiquen ni científica ni metodológicamente el diferir la publicación de los corpora temáticos globales.

\section{Nuevas enCUestas en AStURias a PRINCIPIOS DE Siglo}

a) Encuestas de Josefina Sela (1914-1920)

Igual que entre 1885 y 1910, Asturias proporcionó en las décadas siguientes buena parte de los hallazgos de mayor interés para el Romancero hispánico, y puede ser útil resaltar la continuidad de las exploraciones en un área privilegiada, y no sólo por la calidad de lo allí recogido. La personalidad de quienes intervinieron en la compilación del Romancero asturiano of rece una excepcional galería de folkloristas, y hombres de letras, desde Amador de los Ríos, Ake W. Munthe y Juan Menéndez Pidal a Llano, Cabal o Martínez Torner, con pocos paralelos en la etnografía peninsular.

En Asturias, el estímulo de Ramón M. Pidal a la labor de recogida de campo se traduce pronto en los casi dos centenares de versiones reunidas entre 1914 y 1916 por una alumna universitaria, Josefina Sela, como prólogo a la magnífica y aún más copiosa colección leonesa que recogería en los años siguientes (1916-1921). 
Josefina Sela (hija del abogado y profesor Aniceto Sela, quien colaboró con Machado Álvarez en los proyectos fundacionales de «El Folklore asturiano» en la década de 1880) aprovechó los veranos que pasaba en Salinas y sus relaciones familiares en Asturias, para iniciar su búsqueda de romances. De los resultados de su primera campaña daba noticia, en ausencia de Menéndez Pidal, en carta a María Goyri; la carta es reveladora de las dudas metodológicas que surgían en la encuestadora novel respecto al valor de las versiones distintas de unos «mismos» romances, o sobre si debía o no aceptar romances remitidos por escrito:

Esperando todos los días encontrar nuevos romances, no he dado a $\mathrm{V}$. antes cuenta de mis gestiones. Llevo hasta ahora reunidos los que le indico en la adjunta nota, y espero aumentar la colección con los que me diga una mujer que he encontrado, sabiendo abondos, cerca de aquí.

Como V. verá, la mayor parte de ellos, la casi totalidad, están ya publicados por Menéndez Pelayo (con ligeras variantes). ¡Ojalá que aun así sirvan de algo!

Además, quería consultarle a V.: hay en otro pueblo, no lejos de aquí, pero cuya llegada no puede ser más que a pie (lo cual me impide por completo mi salud) una vieja que me dicen sabe muchísimos. He conseguido que me mande copiados dos de ellos, los que dicen «no valen nada para todo lo que ella sabe, porque lo hay que dura hora y media» (son sus palabras), y por ese medio creo podrá mandarme todo o la mayor parte de lo que sepa. Mi duda está en si copiados de esa manera (recomiendo por encima de todo exactitud, pero no respondo de ella) pueden servir a Vds. V. me dirá, aguardo para no obligarles a hacer un trabajo inútil. Incluyo ambos tal como han llegado a mí ${ }^{22}$.

A la carta acompaña, en efecto, una lista de los temas recogidos, identificados con remisión a versiones impresas en el tercer volumen de la Antología de Menéndez Pelayo; la colección comprendía un total de treinta y seis textos. En fechas algo posteriores al 5 de septiembre Josefina Sela reunió algunos romances más ${ }^{23}$, que elevan hasta cuarenta y nueve las versiones anotadas en esta primera encuesta de 1914. Se trataba de una de las aportaciones individuales más numerosas, y valiosas, desde la Colección de los viejos romances de 1885. La tradición asturiana representada en esta primera encuesta de Josefina Sela documentaba por primera vez el Romancero de la costa central, es decir el de los concejos de Castrillón, Candamo, Avilés, Illas, Gozón y Carreño.

22 Carta, del 5-IX-1914, fechada en «Salinas, Avilés» (AMP).

23 En carta a María Goyri del 3-VII-1915 alude J. Sela a nuevos textos remitidos que, en parte al menos, deben de corresponder a la encuesta de 1914: «En los últimos días que estuve en Madrid me encontré, entre papeles, con esos romances que quedaron, se conoce, escondidos cuando yo entregué a $\mathrm{Vd}$. los otros. Se los envío juntos con otros dos que me mandan de Oviedo copiados» (AMP). 
Esa era el área que utilizando como centro la localidad de Salinas pudo cubrir la encuestadora; pero a Salinas, por entonces un pueblo de moda para veraneantes, afluían también como empleadas domésticas o al mercado, mujeres del interior de la provincia, y Josefina Sela pudo añadir versiones de Quirós, Infiesto o Llanera.

Los textos, muy completos casi siempre, incluyen versiones excelentes de El conde Claros, La infantina y el caballero burlado, La infanta parida, Flérida y don Duardos, El conde Niño, La merienda del moro Zaide y La muerte del príncipe don Juan, entre varios otros. Por el número de registros cabe destacar las cinco versiones de La Gallarda y las seis de La infanticida; y por su especial interés las primeras versiones asturianas de La Serrana de la Vera, en un tipo diferencial exclusivo del norte de la provincia, y del viejo tema épico del Cid y el conde Lozano, Rodriguillo venga a su padre, que sólo ha reaparecido en áreas tan distantes como Ibiza y Madeira, además de en la versión andaluza muy imperfecta publicada ya por Menéndez Pelayo. Era también primicia absoluta el tema de San Alejo, al que sólo han podido sumarse nuevas versiones ya en la década de 1980.

Al año siguiente Josefina Sela remitió a Menéndez Pidal una nueva colección de versiones. Los textos llevan la indicación «Navidades, 1915. Quirós-Oviedo». Esta encuesta comprende también una cincuentena de textos, restando los de ocasionales informantes de Palencia y León. El área cubierta se centra en localidades de los concejos indicados: El Caleyo, San Salvador, Salcedo, La Concepción, Bárzana, Vallín y La Fábrica, en Quirós; y Piedramuelle, San Pedro de los Arcos, Tudela-Veguín, El Bosque y La Corredoria, en Oviedo. La colectora inauguró este año su costumbre de elaborar listas muy precisas de los romances dictados por cada recitador, como lo haría después en sus encuestas leonesas, lo que posibilita la fácil identificación de sus materiales. En conjunto, los romances recogidos representan una tradición menos arcaica que la del año anterior, con cierto predominio del romancero vulgar y religioso, o versiones «vulgatas» o de romances de hallazgo más frecuente entre los propiamente tradicionales. Con todo, tienen evidente interés las versiones de El robo del Sacramento o Santa Catalina enlazada con Marinero al agua - las primeras que se recogieron en Asturias-, y otras de romances escasamente documentados en la provincia: Silvana, La novia abandonada del conde de Alba, El ateo, etc.

Desde el punto de vista de su «rareza», presenta un interés excepcional la encuesta de Josefina Sela del siguiente año. En 1916 la encuestadora volvió a tomar Salinas como base, y, al margen de algunos textos de una recitadora de Riosa que residía en Salinas, las versiones 
pertenecen todas a los concejos centrales del norte de Asturias: Castrillón, Avilés, Illas, Llanera, Las Regueras y Carreño. Lo más singular es que una mayoría de los textos se deben a una recitadora única, Josefa Braña González, de Tamón, en Carreño, que vivía en Salinas cuando la entrevistó J. Sela. Los veintiséis romances distintos dictados por esta cantora hacen de ella uno de los informantes más excepcionales en la historia de la recolección del Romancero asturiano, superior, incluso, a Teresa Fernández, «la Cana», entrevistada por Juan Menéndez Pidal en 1883, y sólo equiparable a la familia constituida por Anselmo García y sus hijos Domingo y Benigna, de Corralín (Ibias), encuestados por Diego Catalán ya en 1980, o Justo Martínez García, de Tebongo (Cangas de Narcea), localizado por Flor Salazar en la misma campaña de recolección de 1980, y a quien ese mismo año tuve ocasión de volver a encuestar personalmente durante largas horas en Guadarrama y en Cangas, en compañía de Ana Vian y Jon Juaristi, sin llegar a agotar un repertorio folklórico que junto al Romancero incluía cuentos, canción lírica y «etnotextos» de todo tipo. La excepcionalidad de recitadores como los mencionados no consiste sólo en el número de romances que pueden recitar o cantar. Sin ser frecuentes, son varios los informantes que han memorizado un repertorio de veinticinco, cuarenta o incluso más romances distintos. Lo inhabitual es que cada versión sea dictada con absoluta seguridad y sin lagunas, que la mayoría de ellas puedan considerarse como texto excelentior entre todas las que de ese mismo romance se han recogido en el área, y que el repertorio incluya versiones de algunos o varios temas hasta entonces no documentados en la zona, y que no vuelven a serlo después. En ese sentido, el caso de Josefa Braña sólo admite parangón con muy contados cantores de romances: Joan Prat Molins, «Calic», capaz de proporcionar por sí solo un cancionero completo ${ }^{24}$; Juan José Niño, depositario del romancero de los gitanos de la baja Andalucía en la forma más completa que ha podido documentarse, y cantoras sefardíes como Vida de Albilansí, de Lárissa, o Hanna Bennaim, de Tánger, y Simi Chocrón, de Tetuán, entrevistadas por Manrique de Lara a principios de siglo. Son ejemplos señalados de hasta dónde puede alcanzar el desarrollo de la memoria dentro de una cultura oral en plena vitalidad, si bien el carácter ritualizado que ofrece el canto de romances en las tradiciones sefardí y gitano-andaluza hace menos sorprendente los sesenta romances que, por ejemplo, recordaba Vida

${ }^{24}$ El Cançoner del Calic, recollit i ordenat per Joan Serra i Vilaró (Barcelona: L'Avenç, 1913). Los romances, sin embargo, no constituían el género único del repertorio de Joan Prat, ni presentaban en su mayoría caracteres de especial arcaísmo. 
de Albilansí. En otras tradiciones baladísticas han merecido justa atención fenómenos como el de Anna Gordon, Mrs. Brown de Falkland, que a fines del siglo XVIII proporcionó hasta treinta y tres textos de baladas escocesas distintas, de los que veinticuatro fueron publicados por Child como las mejores, o únicas, versiones de los temas baladísticos respectivos; o el de Isabella Robertson, ya en el siglo XIX ${ }^{25}$.

No vamos a tener aquí la oportunidad de tratar de los cantores individuales en la forma que sería deseable. Ignoramos casi todo sobre los recitadores asturianos - y del resto de la Península - del siglo XIX y la primera mitad del $\mathrm{Xx}$, excepto su nombre, edad, y lugar de origen -y aun eso no siempre con exactitud-; sólo en las encuestas más recientes ha sido posible acopiar lateralmente otros datos que nos dicen algo sobre el proceso de aprendizaje del Romancero, las técnicas de actualización, y el significado que la canción narrativa tiene para los recitadores que han continuado transmitiéndolo. No creemos que sean extrapolables al Romancero hispánico las hipótesis que sobre la recreación individual han formulado Buchan y otros al estudiar el caso de Anna Brown dentro de la balada anglo-escocesa ${ }^{26}$. De todos modos, existen también diferencias notables entre unos y otros recitadores de romances en la poesía tradicional hispánica, y hemos creído conveniente

25 Cf. D. Buchan, The Ballad and the Folk (London-Boston: Routledge \& Kegan Paul, 1972), capítulos 7-9 (sobre A. Brown), y 18 (sobre Bell Robertson).

26 Mrs. Brown era persona perteneciente a una clase no estrictamente popular; hija de un profesor de Humanidades, casada con un ministro de la Iglesia, y mujer con cierta formación literaria, que manejaba textos de baladas ya impresas, y con notoria habilidad para repentizar. Se trataría, pues, de una transmisora «activa», excepcional en todas las tradiciones baladísticas. Aun así, el grado de recreación que se le da por supuesto en cada "performance» de una balada es muy posible que hubiera de rebajarse si se conociera un mayor número de versiones registradas en la misma época y área geográfica. Buchan está, tal vez, excesivamente influido por la analogía que quiere trazar con los cantores épicos yugoslavos, y no creo que el examen de las variantes en los textos de Mrs. Brown, tal y como se registran en la edición de Child, apoye en todo la creencia, que comparte con B. Bronson, de que «Mrs. Brown did not accept the concept of the fixed text, but did in fact re-create her ballad-stories». Cierto que el "texto fijo» es ajeno a la balada oral, si la idea no se lleva a sus extremos, pero no advertimos en las variantes ninguna recreación real de las «ballad-stories». A. Bold, que sigue a los estudiosos citados, admite al menos que en el caso de The Lass of Roch Royal (Child, núm. 76) las dos versiones de Mrs. Brown «tell the same story» (The Ballad, 1979, p. 15). Ignoro también en qué medida Buchan y Bronson han tenido en cuenta los retoques a que fueron sometidos los textos de Mrs. Brown por parte de sus primeros editores, Walter Scott y Jamieson. Cf., al respecto, S. B. HustvedT, Ballad Books and Ballad Men. Raids and Rescues in Britain, America, and the Scandinavian North since 1880 (Cambridge, Mass.: Harvard Univ. Press, 1930), pp. 31-32 y 57. 
subrayar aquí la importancia que para nuestro conocimiento de la tradición asturiana han tenido cantores excepcionales como Josefa Braña. La propia Josefina Sela debió de ser consciente del valor de su repertorio romancístico, y la cantora fue reencuestada por Martínez Torner, quien además de las melodías anotó sobre los originales de Sela variantes en los textos y alguna versión de nuevos romances.

De Josefa Braña son las primeras versiones asturianas de La condesa de Castilla traidora, Belardos y Valdovinos, El romero raptor, La princesa degollada por su padre y Sufrir callando, temas romancísticos que o bien no han vuelto a recogerse en la provincia, o sólo en áreas alejadas y en versiones que representan tipos distintos del romance. De ella es también el primer texto de una composición burlesca, $L a$ merienda de las tres comadres, bien documentado en otras regiones pero no en Asturias, y el del romance devoto, Milagro de la mujer caritativa. Incluso en las versiones de romances ya bien conocidos, los textos de J. Braña merecerían muchas veces el primer lugar en una Antología del Romancero asturiano por su excelente calidad poética (casos de $\mathrm{Ge}$ rineldo, La infanta parida, La bermana cautiva hexasilábica, La mala suegra, o La muerte del principe don Juan, entre otros; e incluso en romances vulgares tradicionalizados, como El difunto penitente, La infanticida y La mala hija que amamanta al diablo; o religiosos). El único romance del que la cantora dio una versión «imperfecta» es La bastarda $y$ el segador; y ello no es casual si se tiene en cuenta que la versión fue dictada sólo a Eduardo Martínez Torner, y que la cantora interrumpe el romance por autocensura, como sigue siendo habitual en nuestro días, y no por fallo de memoria, en el momento en que el relato alcanza su más elevado tono erótico.

Junto a los textos de Josefa Braña, la encuesta de 1916 incluye otra veintena de versiones, entre las que deben señalarse un texto muy notable de El veneno de Moriana, y los primeros registros asturianos de Pregunté si habia cena (o Las dos madamas) y A Belén llegar en versiones de Raíces (Castrillón) y La Peral (Illas).

El resto de las aportaciones de Josefina Sela al Romancero asturiano lo constituyen grupos de textos remitidos en su mayoría por distintos colaboradores captados por Sela en el curso de sus encuestas. Los originales son de mano popular, a veces, y no siempre es segura la fecha en que fueron anotados. De 1916 creemos que son las cuatro versiones de Tudela Veguín facilitadas por Generoso Díaz, y otras de Aller, Luanco, Avilés y Mieres. Posterior, acaso ya de 1920 o incluso más tardía, es una colección de catorce versiones de Muriellos (Quirós) remitida en hojas numeradas y en letra que nos es deconocida (quizá de 
Valentín Quiñones), pero con anotaciones en letra de Sela; figura aquí una de las mejores versiones de La penitencia del rey don Rodrigo, y entre coplas líricas y alguna composición narrativa dialectal aparecen también buenos textos de El veneno de Moriana, La novia abandonada del conde de Alba y Cristo testigo. Menor interés tienen las series de textos recogidos en Pillarno, Castrillón, en 1920, aunque algunas de sus nueve versiones sean excelentes, y los remitidos por un antiguo recitador, Crisanto Santa-Marina, de La Corredoria, Oviedo, en fecha incierta.

Gracias a Josefina Sela se conoce la tradición del Romancero de los concejos costeros de la zona central, que apenas había sido explorada antes y no ha vuelto a serlo después con resultados análogos a los obtenidos por Sela. El área rural próxima a la órbita de Avilés y Gijón ha sufrido en su habitat transformaciones especialmente intensas desde los años 1914-1916, y el testimonio de lo recogido por Sela es ya en gran medida irreemplazable; sus versiones son, muchas veces la única evidencia que nos queda de una subtradición del Romancero de Asturias que ofrecía rasgos diferenciales marcados, y de un gran valor por su arcaísmo y por la existencia de tipos estructurales propios en varios de los temas romancísticos que allí eran tradicionales. Las encuestas de Sela nos dan a conocer también el Romancero de algunos concejos del interior, Oviedo y Quirós, igualmente en el área central, en la forma más completa que hasta ahora ha podido documentarse.

\section{b) La labor de Eduardo Martínez Torner}

También en 1914 se inician las encuestas del musicólogo Eduardo Martínez Torner (1888-1955), colaborador del Centro de Estudios Históricos, que comenzó su labor en Asturias y la continuaría luego en varias otras regiones españolas. El propio Torner, que ya antes de 1914 había empezado sus trabajos sobre la música popular asturiana, rememoraba en 1919 cómo y cuándo se produjo su dedicación al campo del Romancero. En un principio, confiesa, fue un criterio más de artista que de musicólogo el que le había impulsado a recoger melodías populares:

Habiendo terminado en 1910 nuestros estudios pianísticos, y deseando comenzar los de la composición musical, creímos que nada mejor que valernos de temas populares de nuestra región para llegar a adquirir una personalidad propia [...] Con tal objeto habíamos comenzado la labor de recopilación, logrando reunir en 
poco tiempo varias decenas de melodías de distinto carácter y seleccionadas con un criterio restringido, dado el interés meramente artístico que entonces nos guiaba ${ }^{27}$.

Posteriormente, las enseñanzas recibidas en la Schola Cantorum de París, junto al maestro d'Indy ${ }^{28}$, en 1912 y 1913, le convencieron de los «valores de carácter científico que, aparte del artístico, encierra la canción popular»,

Mas para que ésta pueda servir de base sólida para estudios científicos es indispensable que sea recogida del pueblo en toda su integridad y transcrita con fidelidad absoluta, desechando al mismo tiempo el criterio restringido con que nosotros habíamos procedido, es decir, anotando todo cuanto el pueblo canta, por insignificante que parezca.

La imposibilidad de continuar sus estudios en París debido a la guerra europea y los consejos de d'Indy le decidieron a reanudar sus trabajos de campo en Asturias (1914) y, a la vez, a emprender el estudio de los antiguos cancioneros.

A este efecto, y para la mejor orientación de nuestros trabajos, nos hemos incorporado, en el Centro de Estudios Históricos, a la sección que dirige el sabio maestro D. Ramón Menéndez Pidal. En 1916, y a propuesta del Centro, la Junta para Ampliación de Estudios e Investigaciones Científicas nos concedió una pensión para recoger romances tradicionales en las provincias de Asturias y León, habiendo logrado reunir 83 romances asturianos y 137 leoneses, todos con sus correspondientes melodías ${ }^{29}$.

La cifra final de versiones de romances recogidos por Torner es, en realidad el doble de la que aquí indicaba, una vez que se tienen en cuenta incorporaciones posteriores y varios textos que, al parecer, no eran considerados como romances por el colector. Como aclara Torner, no incluyó en su Cancionero de 1920 los romances recogidos en Asturias, «porque su música es de índole muy especial» y porque «serán, en su día incluidos en el Romancero español, cuya publicación prepara el Sr. Menéndez Pidal» ${ }^{30}$.

27 Eduardo MARTf́nez TORnER, Cancionero musical de la lírica popular asturiana (Madrid: Nieto, 1920), p. xl.

28 Vincent d'Indy (1851-1931) fue un notable folklorista, adenıás de compositor y profesor de la Schola; a él se debe una colección, póstuma, de Chansons populaires $d u$ Vivarais (Paris: Durand et Cie., 1948), 2 vols.

29 Eduardo MARTINEZ ToRner, Cancionero musical..., pp. xli-xlii. El prólogo está fechado en 1919.

$30 \quad$ Ibid., p. xlii. 
Las colecciones remitidas a Menéndez Pidal por Torner se incorporaron en distintos momentos al archivo de don Ramón, a veces en copia doble y triple. Ocasionalmente figuran también textos sueltos y borradores, sin numeración, que parecen proceder de materiales no copiados definitivamente y no agrupados en colección. En el Centro de Estudios Históricos hubieron de quedar los materiales melódicos de Torner, incluyendo parte de los correspondientes al Romancero, cuando el musicólogo partió al exilio. Después de la incautación por parte del C.S.I.C. de los fondos del Centro, algunas versiones fueron ocasionalmente impresas, sin indicación de su procedencia y con localizaciones geográficas erróneas, en trabajos misceláneos publicados en la Revista de Dialectología. Creemos, con todo, que los materiales de Torner sobre el Romancero asturiano se han conservado completos, salvo lagunas mínimas, y que los originales y copias del Archivo Menéndez Pidal permiten reconstruir por entero las encuestas del gran musicólogo. Cuestión distinta es el que no siempre pueda determinarse con seguridad la fecha y lugar de recolección de algunas versiones.

La primera de las encuestas de Martínez Torner es la que hemos denominado "Asturias 1914», aunque es muy posible que incorpore versiones recogidas en fecha anterior. La colección fue copiada dos veces, al menos, con paginación seguida (1-54) y numeración de los textos en romanos (I-LI). A ellos hemos añadido otros nueve textos sueltos (núms. 52-60), de recitadores o lugares de encuesta que coinciden con los que integran esta primera serie. Creemos que el origen de esta colección está en la copia que Torner hizo para Menéndez Pidal de todos los materiales que consideraba como romances dentro de lo que hasta entonces había recogido; ello explica que excluyese algunas composiciones sin carácter narrativo pleno (núms. 55-57) y algunos romances modernos (59-60) que publicó como textos «líricos» en su Cancionero de 1920. Debido a su carácter de 'recapitulación', la colección presenta cierto aspecto misceláneo en cuanto a su geografía. Predominan las versiones de concejos meridionales: Aller, Riosa, Quirós, Teverga, Lena; pero figuran también textos de la zona oriental: Llanes, Parres, Cangas de Onís; en menor número, de la central: Oviedo, Siero, Avilés; y, por último, dos versiones de Tineo. Las de Aller fueron facilitadas en su mayoría por Valentín Lillo, párroco de Vega de Aller, y en ese primer grupo se encuentran varios de los textos más valiosos.

Las dos siguientes encuestas de Martínez Torner, ya de 1916, tienen mayor unidad geográfica. De ambas contamos también con una doble copia; en la copia primera se anotan los versos en líneas de octosílabos y se numeran independientemente para cada colección las páginas del 
manuscrito. La segunda y definitiva copia, en dieciseisílabos, está en gran parte mecanografiada, e integra esas colecciones asturianas dentro de un conjunto más amplio, es decir el formado por el conjunto de romances de Asturias y León que Torner reunió cuando fue pensionado por la Junta para Ampliación de Estudios. La colección global, que hemos denominado «Norte 1916», incorporó otros materiales, entre ellos los de la encuesta «Sela-Torner 1916», y formaba un impresionante corpus de casi 800 hojas, sin contar las melodías, y 319 versiones distintas de romances, algo nunca visto hasta entones en el Romancero peninsular, si se excluyen las colecciones catalanas de Milá y Aguiló. Aunque Menéndez Pidal desglosó los textos para archivarlos de acuerdo con su clasificación temática del Romancero, la numeración corrida que llevaban las versiones de Torner nos ha permitido reconstruir la colección y situar dentro de ella las distintas secciones de versiones asturianas.

Los 120 primeros textos (hojas 1-312) son versiones leonesas mecanografiadas que formaban parte de una colección unitaria primitiva, «León 1916», de la que se conserva otra copia escrita a mano que ocupaba 257 páginas. A continuación, textos 121-163 (hojas 313-408), Torner copió la colección recogida por Josefina Sela y en parte por él mismo en el Norte de Asturias, a la que ya nos hemos referido. Sigue un tercer grupo formado por un centenar de versiones, textos 164-262 (hojas 409-665), del que también existe una copia a mano previa, con numeración independiente. Esta «subcolección» la integran en su mayoría textos leoneses recogidos en Babia, Luna y Laciana, pero ocasionalmente Torner entrevistó a informantes asturianos que residían en esta zona de León limítrofe con el Principado. La cuarta sección, textos 263-304 (hojas 666-762), la forman versiones de romances asturianos, del noroeste de la provincia, de la que igualmente se conserva otra copia anterior, manuscrita, que ocupaba 128 páginas. Por último se anotaron otras quince versiones asturianas y leonesas, textos 305-319 (hojas 763795), a las que posiblemente Torner pensaba seguir añadiendo otros materiales; los últimos romances copiados son cuatro versiones facilitadas por C. Cienfuegos y es de suponer que a ellos habrían de sumarse otros textos proporcionados por el mismo colector y que nos consta estaban ya en manos de Torner.

Prescindiendo de los romances leoneses y los de la colección SelaTorner, que ya hemos reseñado más arriba, las nuevas aportaciones al Romancero asturiano que se contienen en estas encuestas de Martínez Torner en 1916 son, en primer lugar, un pequeño grupo de diez textos que aparecen intercalados dentro de los materiales recogidos en Babia y Laciana, pero dictados por recitadores naturales de los concejos de 
Cangas de Narcea y Somiedo. De verdadero hallazgo puede calificarse la versión, primera en Asturias y en toda la tradición hispánica moderna, del romance de La bella malmaridada, recitada por una de estas cantoras, Jesusa Sánchez, de Cangas de Narcea, que ocasionalmente residía en Villablino.

Más numerosos son los materiales acopiados en la encuesta posterior, realizada in situ en la costa occidental de Asturias, que dio como resultado una cincuentena de versiones de los concejos de Navia, Coaña, Luarca y Villayón. A continuación de ellas, Torner copió algunos otros textos (núms. 49-55) de procedencia varia (Teverga, Aller, Tineo, Mieres, etc.), que debió de recoger en distinto momento; parece tratarse en algún caso de romances de encuestas anteriores (la de 1914 a juzgar por la coincidencia de algunos de los lugares, y acaso otros de 1915) que en el momento de la copia en limpio se le habían traspapelado. Por último, hemos integrado en esta colección unos textos (núms. 5662) que aparecen en papeles sueltos, pero que creemos que son de esta misma época, por su lugar de recogida o, incluso, sus recitadores. Entre las varias versiones notables de romances que se contienen en la colección, merece destacarse un texto extraordinario por su calidad como poema: la versión (núm. 19) de Dolores García, de Andés (Navia), que funde el raro romance de El idólatra y la tormenta con La princesa peregrina en una de las versiones más bellas y completas que se conocen.

Ya hemos indicado que de todas las encuestas parciales de 1916 o anteriores refundidas por Torner en su gran colección «Norte 1916» se conservan copias anteriores. No todos los romances anotados en la primera copia pasaron a la definitiva; algunas versiones fragmentarias o correspondientes a composiciones líricas y romances vulgares modernos fueron excluidas. En los inventarios de estas encuestas hemos tenido en cuenta las copias primeras, más cercanas al momento de recolección e importantes siempre por contener lecturas y variantes omitidas en la definitiva copia en limpio.

En el Archivo Menéndez Pidal se conservan varios papeles sueltos con originales y copias de versiones o incipit musicales en letra de Torner que no forman colección. Faltan muchas veces los datos de informante, fecha y lugar de recolección, y en ocasiones no es seguro que se trate de textos asturianos. Hemos agrupado los textos que creemos que proceden de Asturias, junto con algunos fragmentos publicados en distintas obras de Torner, en un apartado de «Dispersos, ¿1916?-1929». Esta serie y dos textos más tardíos anotados junto con Jesús Bal en 1931 cierran el inventario de las aportaciones de Martínez Torner al Romancero de Asturias, tal y como hemos podido conocerlas 
a través de unos materiales a los que su colector, el «maestro de los estudios folclóricos españoles» ${ }^{31}$, no pudo dar forma definitiva a causa de su exilio en 1939, pero que por fortuna se han conservado completos, al menos en lo que atañe al Romancero estricto, gracias a su integración en el Archivo de Menéndez Pidal.

Las versiones asturianas de Torner, unas 160 en total, tienen el valor adicional de ser las primeras recogidas junto con sus melodías correspondientes. Antes de él eran contadas las transcripciones musicales existentes del Romancero asturiano: las de Inzenga, escasas y poco dignas de confianza, la que publica Amador de los Ríos, en su Historia crítica de la literatura española, facilitada por el mismo José Inzenga, de una versión de La infanta parida; otras melodías, de El cura sacrílego y La Virgen y el ciego, en versiones de Mieres notadas por Socorro Osuna hacia 1902, que conocemos en copias posteriores de Torner y de Manrique de Lara, y muy pocas más, limitadas al romance de la danza prima ${ }^{32}, o$, curiosamente, al poema culto narrativo de Juan Menéndez Pidal, Lux aeterna, del que ya en 1901 se transcribió la melodía de una versión tradicionalizada en Trubia ${ }^{33}$.

La perspectiva del musicólogo que guiaba a Torner determina también en alguna medida su criterio amplio en la recogida de los textos ${ }^{34}$. El interés musical le llevó a recoger versiones de romances modernos

31 Así fue considerado por el hispanista y musicógrafo inglés J. B. Trend; cf. el prólogo de H. Serís a Lírica hispánica. Relaciones entre lo popular y lo culto (Madrid: Castalia, 1906), p. 11.

32 Cf. del mismo InZENGA, Colección de cantos y bailes populares de España. As turias (Madrid: Ducazcal, 1888). No parecen conservarse unas «Notaciones musicales mss. de la Danza prima, y saleas», de Valentín Zubiaurre, que J. SomozA describe en su Registro asturiano (núm. 1.500) a partir de una referencia de segunda mano, el libro de M. DE Foronda, De Llanes a Covadonga (1893). Pero creemos que tales «Notaciones musicales» se reducen a las dos partituras incluidas en el libro de Foronda, p. 58, de las que la «danza prima» no corresponde a ningún romance.

33 La melodía, facilitada por el propio J. Menéndez Pidal, se publicó en la revista Arte y Letras, «Lux-Aeterna, como se canta en Trubia», Arte y Letras, II, núm. 38 (1901), s. p. Es la misma que publica Torner en su Cancionero musical de 1920, p. 36 (núm. 109).

34 No aludimos aquí a algunas críticas de detalle que recientemente se han formulado a la presunta falta de rigor de que adolecerían las transcripciones de Torner al reflejar las distintas variedades lingüísticas asturianas. Cf. H. Álvarez Hernández y B. GonZÁlez LlOSA, «Algunas observaciones al Cancionero de Torner», Lletres Asturianes, 28 (marzo 1988), pp. 41-45. En esas «observaciones» parece haberse prescindido del hecho bien notorio de que las «letras» de las canciones 'viajan', junto con su música, y son memorizadas, junto con rasgos lingüísticos ajenos al habla del cantor. 
y de composiciones a caballo entre lo narrativo y lo lírico que habían sido desechadas por colectores más centrados en lo textual. Gracias a ello las encuestas de Torner aportan las primeras versiones asturianas de gran número de temas. Entre los romances burlescos de amplia difusión peninsular, se documentan ahora en Asturias: Adúltera con un gato, El vendedor de nabos, El cura pide chocolate, así como varias composiciones pertenecientes a la canción narrativa moderna: Entierro y boda contrastados, Galán que corteja a una mujer casada. Otros tres, otros tres y son seis, El atropellado por el tren, etc. Mayor interés que estas últimas tienen las primeras versiones asturianas de La pastora probada por su hermano, una balada europea que en el ámbito hispánico se conocía sólo en Portugal y Galicia, de Los peregrinos primos o de otros textos que García Lorca, buen conocedor del Cancionero de Torner y oyente privilegiado de las conferencias musicales del maestro asturiano, haría también célebres, como las 'añadas' o canciones de cuna seminarrativas "Todos los trabayos son...» (Triste vida de las mujeres) y «Tengo el mió Xuan en la cama...», un canto de doble sentido, tradicional también en Galicia, que deja traslucir toda una historia previa ${ }^{35}$. A Torner le interesaron igualmente composiciones religiosas semicultas y más o menos "para-narrativas», que se cantaban en un contexto ritual, y anotó también los primeros textos asturianos conocidos de la Petición de ánimas, Nacimiento y posadera despiadada, la Anunciación en pareados, uno de los tipos de la Adoración de los Reyes, El rastro divino (A), Atención al misterio, Cristo justifica su Pasión, el Milagro de San Antonio y los pájaros, etc. Por último, algún interés hubo de ver en las melodías de los romances vulgares, algunos de los cuales se usaban en las danzas, y a él se debe la primera documentación en Asturias de Rosaura la de Trujillo, La renegada de Valladolid en una forma estrófica, El moro piadoso libera a la cautiva, Marcos de Cabra, entre otros.

En suma, las nuevas perspectivas aportadas por Martínez Torner a la recolección del Romancero asturiano supusieron un valioso complemento a lo ya realizado por sus predecesores, sobre todo por incorporar a la investigación de la canción narrativa tradicional el componente melódico, esencial en la transmisión del Romancero; un componente que

35 García Lorca difundió estas y otras «añadas» asturianas que conocía a través de Torner en una conferencia que pronunció por primera vez en diciembre de 1928 - como me indica Mario Hernández-; se publicó en La Habana en 1930, y muerto ya el poeta con los títulos de «Añada, arrolo, nana, vou veri vou. Canciones de cuna españolas» (Buenos Aires: Losada, 1942) y «Las nanas infantiles», por ejemplo en la ed. de Madrid: Aguilar, 1962, pp. 145-169. 
nadie mejor que Torner, asturiano y musicólogo, estaba capacitado para estudiarlo, y para valorarlo artística y científicamente ${ }^{36}$.

\author{
JESÚS-ANTONIO CID \\ Universidad Complutense, Madrid
}

La edición científica del Romancero General Hispánico ha sido un proyecto varias veces abordado, desde mediados del s. XIX, por distintos estudiosos y con criterios muy distintos. Sin embargo, hasta hoy tal proyecto no ha sido llevado a término satisfactoriamente. En la primera parte de este artículo se intenta explicar la razón del fracaso de uno los intentos más sólidos de edición del Romancero, el planeado por el hispanista R. Foulché-Delbosch en colaboración con R. Menéndez Pidal a principios de siglo. Por razones análogas, el Romancero que emprende Menéndez Pidal en solitario hacia 1904 no llegaría a iniciarse hasta varias décadas después. Este último hecho guarda relación - según aquí se sostiene- con el cese de la actividad personal directa de Menéndez Pidal en las encuestas de campo a partir de 1910. Se concluye que la propia riqueza y vitalidad de la tradición moderna de la balada hispánica, insospechadas hasta entonces, obligó a reformular el alcance, organización y dimensiones de la edición global del Romancero, y diferirla hasta obtener un conocimiento suficiente de la tradición oral del Romancero en todas sus ramas geográficas y lingüísticas. Tal conocimiento sólo podía ser resultado de encuestas realizadas por distintos estudiosos o etnógrafos a lo largo de un dilatado plazo de tiempo. En una segunda parte del trabajo se estudian dos de las encuestas más productivas, entre las fomentadas por Menéndez Pidal a partir de 1910: las que llevan a cabo en Asturias Josefina Sela (1914-1920) y el musicólogo Eduardo Martínez Torner (1914-c. 1930).

Since the mid-nineteenth century, the project of a comprehensive scholarly edition of the * Romancero General Hispánico has been undertaken by a number of scholars and from differing methodological approaches. To date, however, this project has yet to be satisfactorily completed. The first part of the present article attempts to explain why one of the soundest of such enterprises, that envisioned by the Hispanist $R$. Foulché-Delbosch in collaboration with R. Menéndez Pidal at the turn of the century, failed to produce a definitive edition of the Romancero. For similar reasons, the edition undertaken single-handedly by Menéndez Pidal around 1904 would not yield results for several decades. The present study argues that this impasse is related to the suspension of Menéndez Pidal's direct personal involvement in field survey work as of 1910. It can be concluded that the sheer richness and vitality of the modern tradition of Hispanic

36 La labor de Martínez Torner no se limitó a las encuestas que realizó personalmente. En ocasiones recurrió también a la ayuda de amigos y colaboradores (F. Vigil, V. Lillo, R. Uría) para añadir materiales nuevos a su colección, y estimuló el trabajo de campo de algunos aficionados al folklore local. La aportación más productiva para el Romancero fue la del poeta y folklorista de Luarca, Casimiro Cienfuegos, al que hemos dedicado un breve trabajo monográfico (en prensa en Ástura). 
balladry had been vastly underestimated until then, and that it was thus necessary both to reformulate the range, organizing principles, and dimensions of a comprehensive edition of the Romancero and to postpone the editorial undertaking until all of the geographic and linguistic manifestations of the oral ballad tradition were sufficiently well understood. Such knowledge could be supplied only by field surveys conducted by various scholars and ethnographers over a broad span of time. The second part of this article examines two of the more productive field surveys among those advocated by Menéndez Pidal as of 1910. Both were conducted in Asturias, respectively by Josefina Sela (1914-1920) and the musicologist Eduardo Martínez Torner (1914-c. 1930). 